\title{
Lung function in healthy British women
}

\author{
A M HALL, C HEYWOOD, AND J E COTES \\ From the MRC Pneumoconiosis Unit, Llandough Hospital, Penarth, Glamorgan CF6 1XW, UK
}

\begin{abstract}
The forced expiratory volume, total lung capacity, transfer factor (diffusing capacity), and their subdivisions have been measured in 113 healthy British women aged 27 to 74 years of whom 47 were current smokers and 66 were lifetime non-smokers. The results have been analysed in terms of age, stature, mass, body fat, and smoking. In addition to their relation to stature and to age, the inspiratory capacity was positively correlated with indices of body muscle while the residual volume, expiratory reserve volume, and total lung capacity were inversely correlated with the percentage of body mass that is fat or with mass divided by the square of stature. The inverse correlation between total lung capacity and age was apparently due to the quantity of body fat increasing with age. The transfer factor and its subdivisions were inversely correlated with smoking. In this study the forced expiratory volume and vital capacity were independent of both fat and smoking; the transfer factor was independent of the physiological response to exercise. The results provide reference values for lung function in British women.
\end{abstract}

Reference values for indices of lung function in healthy women are available from several sources but since the pioneer work of Needham et al (1954) few series have been reported from Britain. This paper describes the results for 113 healthy women in England and Wales of whom most were identified by a process of random sampling from the communities where they lived and who attended for a study of the physiological response to exercise (Cotes et al, 1974). The present results provide reference values for lung function in such subjects.

\section{Subjects and methods}

We studied 141 subjects who were drawn from three separate investigations, and the results were pooled after it had been established that there were no significant differences between them. Seventyseven women were recruited from sampling randomly chosen houses in the Vale of Glamorgan, 21 from sampling the lists of general medical practitioners in Splott, Cardiff, and 43 from the domestic and academic staff of the Carnegie College of Physical Education, Leeds. The subjects completed the MRC questionnaire on respiratory symptoms and underwent clinical interview and examination; they were all considered to be in good health at the time of the study. None had chronic bronchitis as defined (Medical Research Council, 1965).

The forced expiratory volume and vital capacity were measured using a McDermott bellows spirometer. The result used for the analysis in the case of the forced expiratory volume was the mean of three technically satisfactory blows after two practice attempts. The forced vital capacity was the mean of two determinations obtained on the last of three forced expirations and on one subsequent expiration. The total lung capacity and its subdivisions were measured by the helium dilution closed circuit method with the subject seated upright using a resparameter (Morgan), and this apparatus was also used for the measurement by the single breath carbon monoxide method of the transfer factor for the lung, (diffusing capacity), the diffusing capacity of the alveolar capillary membrane, and the volume of blood in the lung capillaries. The stature was measured using a stadiometer (Holtain). The percentage of body weight that is fat was estimated from the body mass and the skinfold thickness at four sites. The percentage was used both as an index of adiposity and to derive the fat free mass. The latter, when divided by the square of the stature, was used as an index of muscularity. All these measurements, which were made on a single occasion, are described in detail elsewhere (Cotes, 1979). 
The analysis relates to the 113 subjects for whom complete data were obtained and who were either current smokers (47) or non-smokers (66), the exsmokers being excluded. In the analysis the results for the diffusing capacity of the alveolar capillary membrane and the volume of blood in the lung capillaries were used in the reciprocal form in which they were derived; the $5 \%$ level of probability was accepted as significant.

\section{Results}

The mean values and ranges for the age, height, and mass of the subjects and for their lung function are given in table 1 . Table 2 gives the linear regression relation on height and age or mass where these contribute significantly to the description of the findings. Table 3 gives an expanded form of the relation including a term or terms for current smoking, body fat, and other anthropometric variables where these significantly reduced the scatter about the linear regression equation.

Table 1 Mean values and ranges for the indices used in the analysis $n=113$

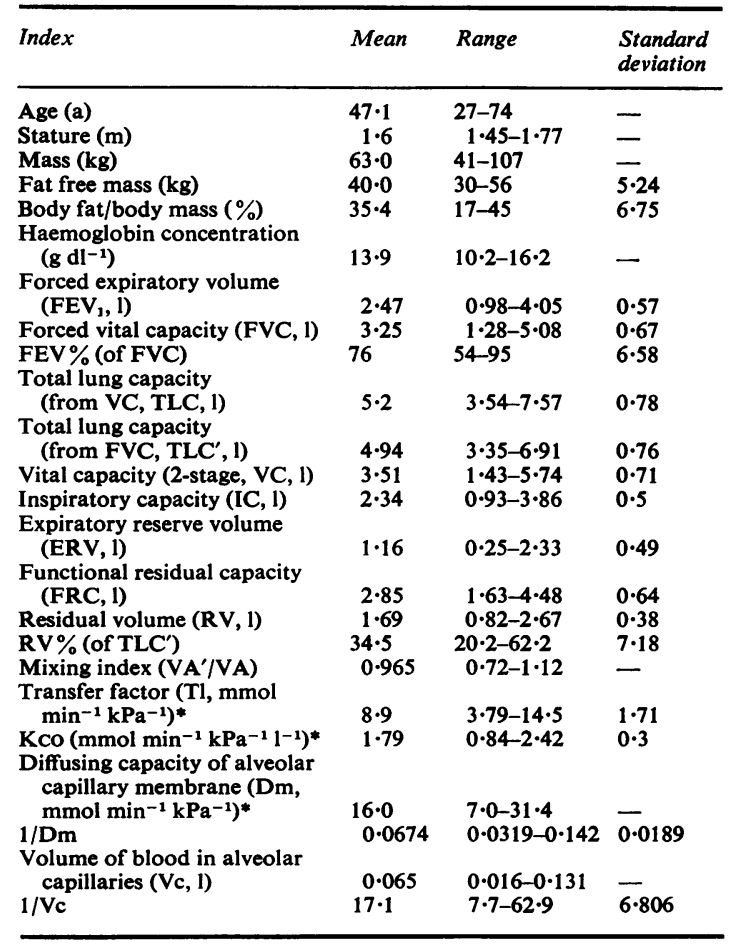

* To convert from mmol $\mathrm{kPa}^{-1}$ to $\mathrm{ml} \mathrm{STPD,} \mathrm{mmHg}{ }^{-1}$ multiply by 2.99 . $\mathrm{KCO}=$ transfer factor $\div$ alveolar volume.
Table 2 Regression equations of lung function on age, stature, and, for FRC, body mass where these terms are significant. (For abbreviations, symbols, and units see table 1)

\begin{tabular}{|c|c|c|c|c|c|}
\hline & \multicolumn{2}{|c|}{ Coefficients on } & \multirow{2}{*}{$\begin{array}{l}\text { Constant } \\
\text { term }\end{array}$} & \multirow{2}{*}{$\begin{array}{l}\text { Standard } \\
\text { deviation }\end{array}$} & \multirow{2}{*}{$\begin{array}{l}\text { Coefficient } \\
\text { of } \\
\text { variation } \\
(\%)\end{array}$} \\
\hline & $A g e^{*}$ & Stature & & & \\
\hline FEV & -0.029 & $3 \cdot 29$ & $-1 \cdot 42$ & 0.36 & $14 \cdot 7$ \\
\hline FVC & -0.29 & $4 \cdot 663$ & $-2 \cdot 88$ & 0.44 & $13 \cdot 4$ \\
\hline FEV \% & -0.222 & - & $86 \cdot 53$ & $6 \cdot 18$ & $8 \cdot 1$ \\
\hline TLC $^{\prime}$ & -0.0126 & $7 \cdot 461$ & -6.42 & 0.51 & $10 \cdot 4$ \\
\hline VC & -0.029 & $4 \cdot 97$ & $-3 \cdot 11$ & 0.47 & $13 \cdot 4$ \\
\hline IC & - & $3 \cdot 41$ & $-3 \cdot 12$ & 0.44 & $18 \cdot 8$ \\
\hline FRC & $-0.031^{*}$ & $6 \cdot 6$ & $-5 \cdot 76$ & 0.43 & $15 \cdot 0$ \\
\hline ERV & -0.025 & $1 \cdot 74$ & -0.44 & 0.36 & $31 \cdot 2$ \\
\hline RV & 0.016 & $2 \cdot 797$ & $-3 \cdot 54$ & 0.31 & $18 \cdot 6$ \\
\hline RV \% & 0.43 & - & $14 \cdot 33$ & $5 \cdot 68$ & $16 \cdot 4$ \\
\hline T1 & -0.036 & $9 \cdot 43$ & $-4 \cdot 53$ & $1 \cdot 51$ & $17 \cdot 0$ \\
\hline $\begin{array}{l}\mathrm{KCO} \\
1 / \mathrm{Dm} \times 10^{-3}\end{array}$ & NSR & & & & \\
\hline $1 / \mathrm{Dm} \times 10^{-3}$ & 0.42 & -63 & 146 & $1 \cdot 76$ & $25 \cdot 9$ \\
\hline $\begin{array}{l}\text { 1/Vc } \\
\mathbf{V A}^{\prime} / \mathrm{VA}\end{array}$ & $\overline{N S R}$ & $26 \cdot 9$ & $60 \cdot 0$ & $6 \cdot 59$ & $38 \cdot 4$ \\
\hline
\end{tabular}

*For FRC the coefficient is on body mass (kg), not age.

NSR $=$ No significant relationship on stature or age or both (except in the presence of other variables, see table 3 ).

Table 3 Regression equations of lung function on age $(A)$, stature $(S t)$, and other variables where these are significant, including current smokers $(\mathrm{Sm})$ as compared with never smoked, body mass $(M)$, fat free mass (FFM), and body fat as percentage of body mass $(F)$. (For abbreviations, symbols, and units see table 1)

\begin{tabular}{|c|c|c|c|}
\hline & & $S D$ & $\begin{array}{l}C \text { of } V \\
(\%)\end{array}$ \\
\hline $\begin{array}{l}\text { FEV \% } \\
\text { IC }\end{array}$ & $\begin{array}{l}89.2-0.248 \mathrm{~A}-3.45 \mathrm{Sm} \\
-5.25+3.48 \mathrm{St}+0.131 \mathrm{FFM} / \mathrm{St}^{2} \\
-4.55-0.008 \mathrm{~A}+3.66 \mathrm{St}+0.058 \mathrm{M} / \mathrm{St}^{2}\end{array}$ & $\begin{array}{l}5 \cdot 93 \\
0 \cdot 39\end{array}$ & $\begin{array}{r}7 \cdot 8 \\
16 \cdot 4\end{array}$ \\
\hline FRC & $\begin{array}{l}-1.90+0.016 \mathrm{~A}+3.90 \mathrm{St}-0.0065 \mathrm{~F} \\
-1.53-0.0024 \mathrm{~A}+4.16 \mathrm{St}-0.089 \mathrm{M} / \mathrm{St}^{2}\end{array}$ & 0.43 & 14.9 \\
\hline ERV & $\begin{array}{l}0.92-0.011 \mathrm{~A}+1.31 \mathrm{St}-0.038 \mathrm{~F} \\
1.26-0.021 \mathrm{~A}+1.41 \mathrm{St}-0.056 \mathrm{M} / \mathrm{St}^{2}\end{array}$ & 0.31 & $26 \cdot 4$ \\
\hline RV & $\begin{array}{l}-2.83+0.027 \mathrm{~A}+2.65 \mathrm{St}-0.028 \mathrm{~F} \\
-2.79+0.019 \mathrm{~A}+2.75 \mathrm{St}-0.032 \mathrm{M} / \mathrm{St}^{2}\end{array}$ & 0.51 & $16 \cdot 1$ \\
\hline TLC $^{\prime}$ & $\begin{array}{l}-5.60+7.39 \mathrm{St}-0.036 \mathrm{~F} \\
-6.26+7.82 \mathrm{St}-0.054 \mathrm{M} / \mathrm{St}^{2}\end{array}$ & 0.47 & $9 \cdot 5$ \\
\hline RV\% & $\begin{array}{l}19.8+0.55 \mathrm{~A}-0.31 \mathrm{~F} \\
20.9+0.45 \mathrm{~A}-0.31 \mathrm{M} / \mathrm{St}^{2}\end{array}$ & $5 \cdot 4$ & $15 \cdot 5$ \\
\hline $\mathrm{Tl}^{*}$ & $\begin{array}{l}-2.77-0.062 \mathrm{~A}+9.46 \mathrm{St}-3.84 \mathrm{Sm}+ \\
0.03 \mathrm{~A} \times \mathrm{Sm}\end{array}$ & $1 \cdot 36$ & $15 \cdot 3$ \\
\hline $\begin{array}{l}\text { Kco } \\
1 / \mathrm{Dm}\end{array}$ & $\begin{array}{l}4.46-0.021 \mathrm{~A}-0.67 \mathrm{Sm}+0.087 \mathrm{M} / \mathrm{St}^{2} \\
0.134+0.00072 \mathrm{~A}-0.066 \mathrm{St}+\end{array}$ & 0.74 & $14 \cdot 0$ \\
\hline $1 / \mathrm{Vc}$ & $\begin{array}{l}0.044 \mathrm{Sm}-0.00074 \mathrm{~A} \times \mathrm{Sm} \\
62 \cdot 7-29.2 \mathrm{St}+3.5 \mathrm{Sm} \\
80.0-29.8 \mathrm{St}-0.95 \mathrm{FFM} / \mathrm{St}^{2}\end{array}$ & $\begin{array}{l}0 \cdot 016 \\
6 \cdot 6 \\
6 \cdot 7\end{array}$ & $\begin{array}{l}24 \cdot 5 \\
38 \cdot 4 \\
38 \cdot 8\end{array}$ \\
\hline
\end{tabular}

*When expressed as $\mathrm{Tl} / \mathrm{St}^{2}$ the $\mathrm{A} \times \mathrm{Sm}$ term is no longer significant. $\mathbf{S D}=$ Standard deviation $; \mathrm{C}$ of $\mathrm{V}=$ Coefficient of variation.

\section{Discussion}

The present results relate to 113 asymptomatic and presumably healthy women from two geographically distinct parts of the UK; they embrace all social classes, a wide range of occupations, and 
also smokers and non-smokers in about equal numbers. The sample is biased in that subjects were excluded who would not undertake a short period of submaximal exercise on a cycle ergometer. This criterion probably led to the loss of some subjects with a low capacity for exercise who, compared with physically active subjects, might have had below average values relative to age and stature for the vital capacity and the transfer factor. Nevertheless, while the evidence for a high level of habitual activity being associated with superior lung function is relatively good (Cotes, 1979) the evidence for a converse effect of inactivity is meagre and its magnitude likely to be unimportant. The measurements were made by experienced workers using standard equipment so that, while the tests were only applied on one occasion there is no reason to doubt their freedom from systematic error. Greater accuracy would have been achieved by the measurements being made in duplicate but the effect of this on the scatter of results about significant regression relation-for instance, on age and stature-is relatively small (Berry, 1974). Thus in the absence of more comprehensive information the present results indicate the lung function to be expected for healthy British women of European descent living in pollution-free parts of England and Wales.

The indices of lung function have been regressed on age and stature, and the absolute levels of these results are discussed in the next paragraph. The extent to which age and stature contribute to the overall variability is in line with the findings of other studies. The effects of smoking are discussed subsequently. In addition to these variables the lung function is influenced by other body dimensions including the percentage of body mass that is fat and mass divided by stature squared (table 3). In the presence of stature or age or both, the inclusion of either of these variables (which are themselves correlated, $r=0.77$ ) significantly reduces the scatter about the regression lines on age and stature for the total lung capacity and its subdivisions, the functional residual capacity (including both the residual volume and the expiratory reserve volume), and the inspiratory capacity, also for the residual volume as a percentage of total lung capacity. Most of the volumes are reduced with an increased amount of fat (eg figs 1 and 2), but in the case of the inspiratory capacity the association is a direct one; however it is no longer significant when indices of muscularity including fat free mass divided by stature squared or mass divided by stature squared are also included in the equation. A similar result has

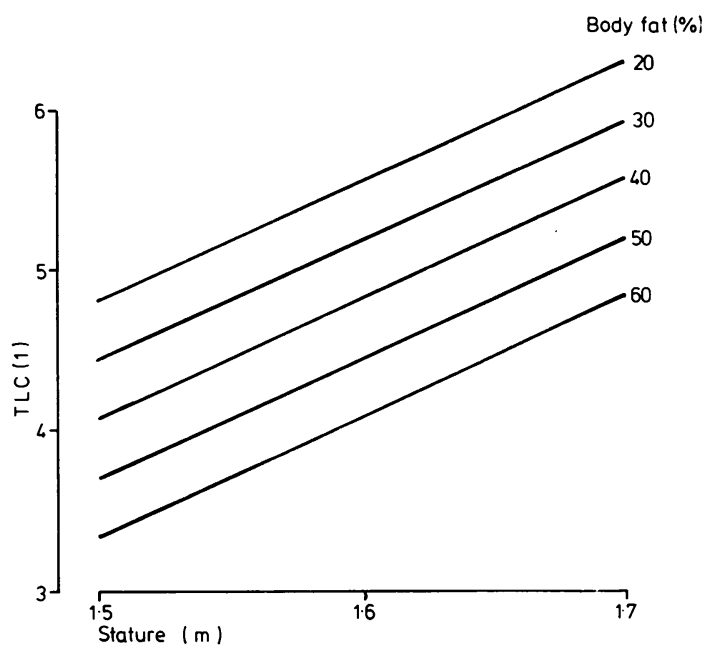

Fig 1 Relation of total lung capacity (TLC) to stature and percentage body fat in healthy women.

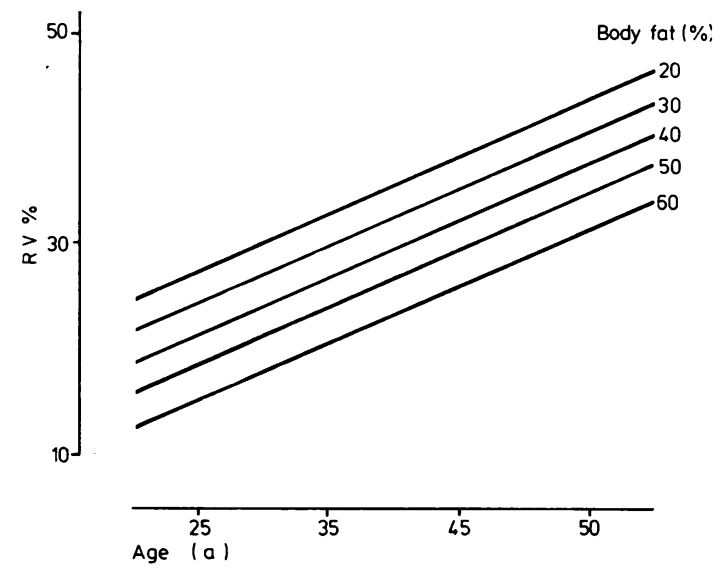

Fig 2 Relation of residual volume as percentage of total lung capacity $(R V \%)$ to age and percentage body fat in healthy women.

been obtained recently for children (Cotes et al, 1979). Thus fat encroaches on the constituents of the functional residual capacity while the inspiratory capacity is related directly to muscularity with which the percentage fat is weakly correlated. In the case of the total lung capacity the effect of adiposity predominates and also explains the association with age that is observed in most series for women (table 2) but not usually for men. For vital capacity the two opposing effects of fat and muscle apparently neutralise each other as this index and the forced expiratory volume are independent of the percentage fat. The mechanism is probably not in doubt except for the residual 
volume where either there is permanent closure of some airways or the alveolar size is reduced or the bronchomotor tone is increased. The present results do not illuminate these alternatives, but other evidence suggests that the first is the most probable (Ulmer et al, 1970); a similar effect of fat on the lung volumes has been observed by others (Amrein et al, 1970). Of the indices of gas exchange only the $\mathrm{KcO}$ is associated with the bodily proportions; the change is in the direction of an increase in body fat or in mass, or fat free mass, divided by stature squared, being accom- $\Rightarrow$ panied by an increase in Kco. This may reflect the inverse relationship of Kco to total lung capacity with which these indices are inversely correlated.

The absolute level of the results after stan- $\frac{\bar{D}}{\partial}$ dardising for age and stature are compared with $\stackrel{\mathbb{Q}}{\complement}$ those for other studies (figs 3-6). These show that, 8 neglecting any effect of smoking, the levels for $\vec{A}$ forced vital capacity are similar to those reported by Dutch workers (Tammeling, 1961; Quanjer, $\vec{\omega}$ personal communication to JEC, 1978)) and in the
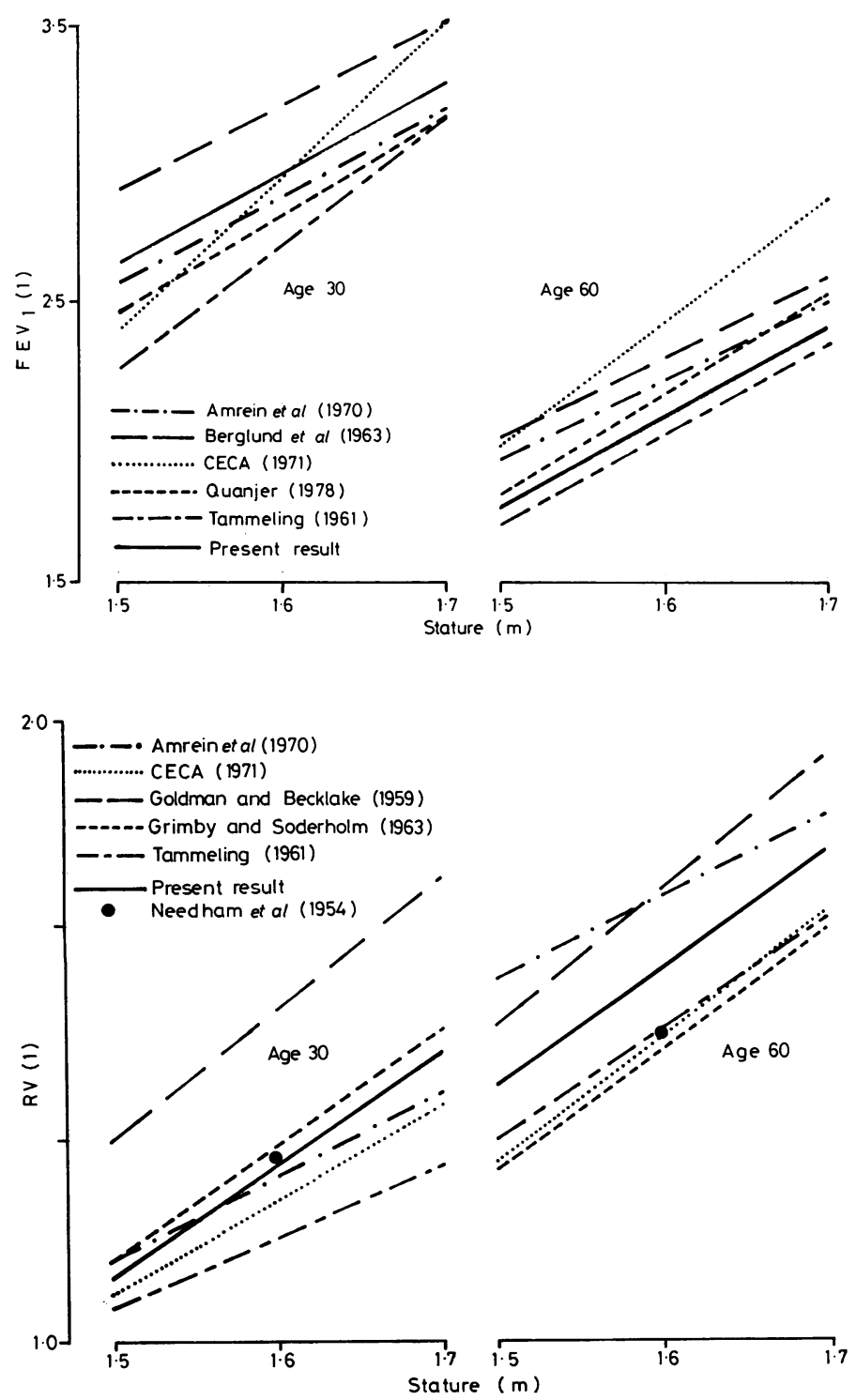

Fig 3 Reference values for forced expiratory volume $\left(F E V_{1}\right)$ in healthy European women. The results of Quanjer (1978) are a personal communication to $J E C$ : for other sources see references.

Fig 4 Reference values for residual volume $(R V)$ in healthy European women. For sources see references. 


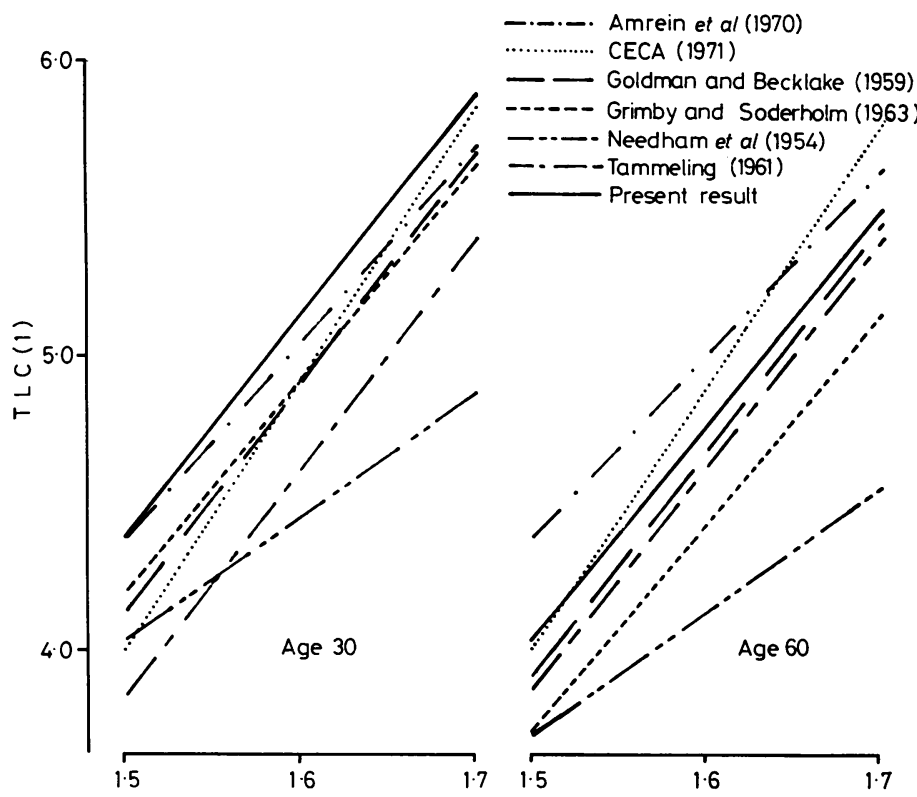

Fig 5 Reference values for total lung capacity $(T L C)$ in healthy European women. For sources see references.

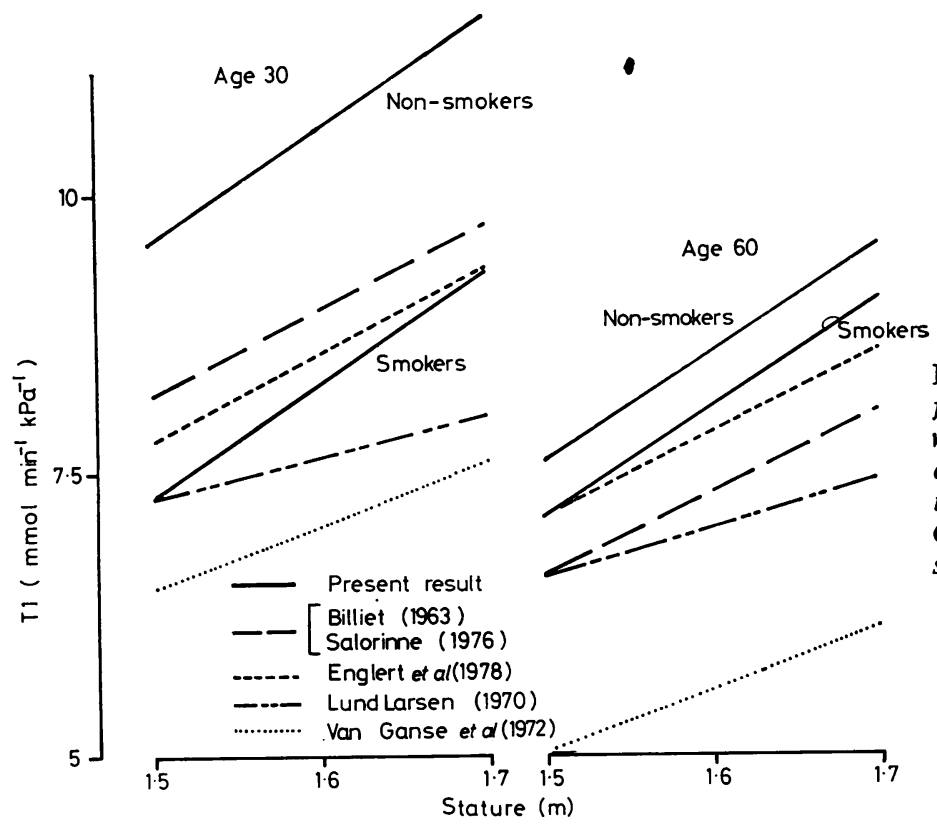

Fig 6 Reference values for transfer factor (diffusing capacity, Tl) in healthy women. The results of Englert et al (1978) are a personal communication to JEC: those of Larsen (1970) are cited by Cotes and Hall, 1970; for other sources see references.

case of younger women by workers in Scandinavia (Berglund et al, 1963) but rather lower than for the women in heavy industry reported by the European Coal and Steel Community and for women in the Swiss electrical industry (Amrein et al, 1970). This latter disproportion which relates particularly to the taller subjects, has been noted previously (Cotes et al, 1966; Smidt and Nerger, 1976). Relative to the forced vital capacity the forced expiratory volume of the present subjects is slightly larger than in some other series, probably reflecting the low levels of atmospheric pollution and the exclusion of subjects with chronic bronchitis. By contrast to the forced 
vital capacity where the present results lie near to the middle of the reported range, the values for the two-stage vital capacity are relatively large; they exceed the FVC by on average 0.261 . Both vital capacities have been used for calculation of total lung capacity.

The residual volume of the UK subjects is in the main intermediate between that reported by Needham et al (1954) and by Goldman and Becklake (1959), both of whom used the closed circuit helium dilution method. The present results are rather larger than those found by the other workers who often used different methods. The reasons for the discrepancy are unclear. It leads to the level of total lung capacity being rather more similar between most of the series than is the case for its two main constituents. The main exception is the total lung capacity calculated from the two-stage vital capacity in the present study. This yields results that are consistently higher than in any other series. The difference probably reflects mainly the procedure for measurement and suggests that the commonly assumed identity between the forced and the two-stage vital capacity that is based mainly on study of men and of children (Cotes et al, 1973b) may not obtain for women.

The values for transfer factor are higher than have been reported previously (see fig 6 for references) but in the case of the Kco the results for smokers and non-smokers separately resemble those in other series (fig 7). Transfer factor is the product of Kco and alveolar volume. Thus while the $\mathrm{Kco}$ is influenced by many factors these are unlikely to be the cause of the high Tl. Instead this is due mainly to the alveolar volume being of above average size. The reasons may be partly technical though we believe this to be unlikely or a reflection of the level of habitual activity of our subjects. To investigate this aspect an association was sought between the transfer factor and the cardiac frequency during submaximal exercise with and without allowance for fat free mass (Cotes et al, 1973a); the expected relationship was obtained between cardiac frequency and fat free mass but the inclusion of cardiac frequency did not reduce the variability about the relation of the transfer indices on age, stature, and smoking. This negative result suggests that the level of habitual activity is not the cause of the high values but does not exclude it. Thus further studies are needed. The need is reinforced by the observation that lower values for the transfer factor have been reported previously from several laboratories, including that of Englert as well as our own (see Cotes and Hall, 1970, for references).

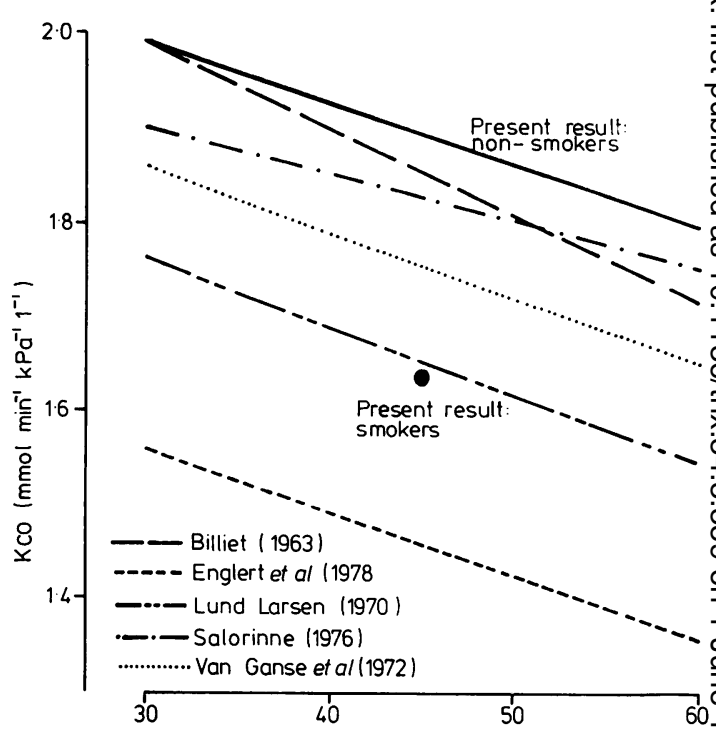

Fig 7 Reference values for $\mathrm{KCO}$ (transfer factor per litre of alveolar volume) in healthy women. For sources see caption to fig 6 .

The effect of smoking on the function of the lungs is well reported; however in most instances

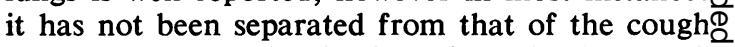
and phlegm to which it gives rise (Fletcher et al, $\overrightarrow{\overrightarrow{\vec{P}}}$ 1976). In the present instance when this is done 3 the deleterious effect of smoking is apparent in the case of the $\mathrm{FEV} \%$, the inspiratory capacity, the transfer factor, the $\mathrm{KcO}$, the diffusing capacity of the alveolar capillary membrane, and the volumeo of blood in the alveolar capillaries. There is a similar trend for the functional residual capacity, ${ }_{-}$ but it is not statistically significant. The effect is in most instances additive and independent of age (table 3 ) but in the case of the inspiratory capacity? it disappears when indices of muscularity are alsoo included in the regression equation. In the case of the transfer factor and its subdivisions there iso an additional interaction between age and smoking; the decline in transfer factor with age beingo greater in the non-smokers than in the smokers $N$ (table 3, fig 6). The difference might be due to the subjects whose lungs were most affected byo smoking giving up the habit, but analysis of the results for the ex-smokers among the present $t_{\overparen{C}}^{-}$ women suggests that this is unlikely. Instead the $\stackrel{\infty}{+}$ trend probably reflects self-selection on the part of the older generation leading to those with lesso robust lungs not taking up the habit at a time when $\overparen{\odot}$ smoking among women was less prevalent than it is today.

More study is needed to explore further the 
effects of the many factors that influence the function of the lungs; meanwhile the results provide useful reference values for the lung volumes and ventilatory capacity of healthy British women.

We are indebted to our subjects for their participation, Miss $\mathbf{J} \mathbf{M}$ Dabbs for making some of the measurements, Mr G Berry for statistical advice, Dr G J Miller for commenting on the manuscript, Dr P Quanjer for allowing us to show in figs 3-7 the reference values of some other workers that he had prepared for another purpose, and $\mathrm{Mr} \mathbf{R ~ T}$ Harris for the photographs.

\section{References}

Amrein, R, Keller, R, Joos, H, and Herzog, H (1970). Valeurs théoriques nouvelles de l'exploration de la fonction ventilatoire du poumon. Bulletin de Physiopathologie Respiratoire, 6, 317-349.

Berglund, E, Birath, G, Bjure, J, Grimby, G, Kjellmer, I, Sandqvist, L, and Söderholm, B (1963). Spirometric studies in normal subjects. 1. Forced expirograms in subjects between 7 and 70 years of age. Acta Medica Scandinavica, 173, 185-192.

Berry, G (1974). Longitudinal observations, their usefulness and limitations with special reference to the forced expiratory volume. Bulletin de Physiopathologie Respiratoire, 10, 643-655.

Billiet, L, Baiser, W, and Naedts, J P (1963). Effet de la taille, du sexe et de l'age sur la capacité de diffusion pulmonaire de l'adulte normal. Journal de Physiologie, 55, 199-200.

CECA (1971). Aide-Mémoire of Spirographic Practice for Examining Ventilatory Function, 2nd edn. Commission of the European Communities, Luxembourg. Industrial Health and Medicine, Series No 11 .

Cotes, J E (1979). Lung Function. Assessment and Application in Medicine, 4th edn. Blackwell, Oxford.

Cotes, J E, Berry, B, Burkinshaw, L, Davies, C T M, Hall, A M, Jones, P R M, and Knibbs, A V (1973a). Cardiac frequency during submaximal exercise in young adults; relation to lean body mass, total body potassium and amount of leg muscle. Quarterly Journal of Experimental Physiology, 58, 239-250.

Cotes, J E, Dabbs, J M, Hall, A M, Axford, A T, and Laurence, K M (1973b). Lung volumes, ventilatory capacity, and transfer factor in healthy British boy and girl twins. Thorax, 28, 709-715.

Cotes, J E, Dabb3, J M, Hall, A M, Heywood, C, and Laurence, K M (1979). Sitting height, fat free mass and body fat as reference variables for lung function in healthy British children. Annals of Human Biology. In press.

Cotes, J E, and Hall, A M (1970). The transfer factor for the lung; normal values in adults. In Normal Values for Respiratory Function in Man, edited by P Arcangeli, pp 327-343. Panminerva Medica, Torino.

Cotes, J E, Hall, A M, Johnson, G R, Jones, P R M, and Knibbs, A V (1974). Decline with age of cardiac frequency during submaximal exercise in healthy women. Journal of Physiology, 238, 24P$25 P$.

Cotes, J E, Rossiter, C E, Higgins, I T T, and Gilson, J C (1966). Average normal values for the forced expiratory volume in white Caucasian males. British Medical Journal, 1, 1016-1019.

Fletcher, C M, Peto, R, Tinker, C, and Speizer, F E (1976). The Natural History of Chronic Bronchitis and Emphysema. Oxford University Press, London.

Goldman, H I, and Becklake, M R (1959). Respiratory function tests. Normal values at median altitudes and the prediction of normal results. American Review of Tuberculosis, 79, 457-467.

Grimby, G, and Söderholm, B (1963). Spirometric studies in normal subjects. III Static lung volumes and maximum voluntary ventilation in adults with a note on physical fitness. Acta Scandinavica, 173, 199-206.

Medical Research Council (1965). Definition and classification of chronic bronchitis for clinical and epidemiological purposes. Lancet, 1, 775-779.

Needham, C D, Rogan, M C, and McDonald, I (1954). Normal standards for lung volumes, intrapulmonary gas-mixing, and maximum breathing capacity. Thorax, 9, 313-325.

Salorinne, Y (1976). Single breath pulmonary diffusing capacity. Reference values and application in connective tissue diseases and in various lung diseases. Scandinavian Journal of Respiratory Diseases, Suppl 96, 1-84.

Smidt, U, and Nerger, $\mathrm{K}$ (1976). Atemwegs und Lungenkrankheiten, 2, 174-191.

Tammeling, G J, (1961). Standard values for lung volumes and ventilatory capacity of sanatorium patients. Selected Papers. Royal Netherlands Tuberculosis Association, 1, 65-89.

Ulmer, W T, Reichel, G, and Nolte, D (1970). Die Lungenfuncktion. Physiologie und Pathophysiologie Methodik. Georg Thieme, Stuttgart.

Van Ganse, W F, Ferris, B G jun, and Cotes, J E (1972). Cigarete smoking and pulmonary diffusing capacity (transfer factor). American Review of Respiratory Disease, 105, 30-41.

Requests for reprints to: Dr J E Cotes, MRC Pneumoconiosis Unit, Llandough Hospital, Penarth, Glamorgan CF6 1XW. 